\title{
Biological monitoring to assess exposure from use of isocyanates in motor vehicle repair
}

\author{
N R Williams, K Jones, J Cocker
}

\begin{abstract}
Objectives-To develop a method for the measurement of a metabolite of hexamethylene diisocyanate (HDI), an isocyanate, and use it to assess the exposure of sprayers employed in motor vehicle repair shops.

Methods-Urine samples were taken from sprayers wearing personal protective equipment and spraying in booths or with local exhaust ventilation, from bystanders, and from unexposed subjects. Samples were analysed for a metabolite of HDI, hexamethylene diamine (HDA), by gas chromatogaphy-mass spectrometry (GC-MS).

Results-HDA was detected in four sprayers and one bystander out of 22 workers. No HDA was detected in the urine of unexposed subjects.

Conclusions-Exposure to isocyanates still occurs despite the use of personal protective equipment and the use of a booth or extracted space. Health surveillance is likely to be required to provide feedback on the adequacy of controls even if such precautions are used and to identify cases of early asthma. Biological monitoring can provide a useful additional tool to assess exposure and the adequacy of controls in this group of exposed workers.

(Occup Environ Med 1999;56:598-601)
\end{abstract}

Keywords: isocyanate; health surveillance; biological monitoring

Isocyanates are highly reactive chemicals used in two component spray paints, adhesives, and in the manufacture of polyurethanes. They may also be released during cutting and welding of materials. Isocyanates are the commonest identified cause of occupational asthma in national ${ }^{1}$ and regional ${ }^{2}$ reporting schemes with the job title "spray painter" being the most commonly specified job. ${ }^{1}$

Various methods have been reported for the measurement of isocyanates in air $^{3}$ and there has been considerable effort to improve the reliability of these methods. However, problems still remain. As control of exposure usually relies on air fed full face respirators, overalls, and gloves and the use of ventilated booths or ventilated spaces, air monitoring will give no indication of the actual exposure a worker receives. The efficacy of such measures to prevent exposure, subsequent sensitisation, and the development of occupational asthma is not well established. Biological monitoring has the potential to measure a worker's body burden received by all routes of exposure (oral, inhalation, and dermal).

Because of the frequency of occupational asthma in this group, workers using isocyanates are required to undergo health surveillance unless the risk assessment carried out under the Control of Substances Hazardous to Health Regulations 1994 (COSHH) draws the conclusion that there is little or no risk to their health from their workplace activities. ${ }^{4}$

Several studies have reported that dermal contact with isocyanates can induce respiratory symptoms in animals ${ }^{56}$ indicating that isocyanates may be dermally absorbed and biological monitoring has been used to study dermal absorption in humans. ${ }^{7}$ Whether dermal absorption, if it occurs in humans, has any potential to lead to respiratory sensitisation is also unknown. Being able to estimate exposure to isocyanates through the development of a urinary assay for metabolites may be a useful way of assessing exposures by respiratory or dermal contact and the effectiveness of control measures.

1,6-Hexamethylene diisocyanate (OCN $\left(\mathrm{CH}_{2}\right)_{6} \mathrm{NCO}$, (HDI)) is widely used in two component spray paints by the motor vehicle repair industry and is finding increasing use as a replacement for toluene diisocyanate. ${ }^{8}$ Most HDI prepolymer based car paints contain a complex mixture of HDI monomers, polymers, HDI biuret, etc, but still contain small amounts of free HDI $\left(0.5 \%-1 \%{ }^{9}\right)$.

1,6-Hexanediamine (HDA) has been detected in the urine (after hydrolysis) of car spray painters who use HDI based spray paints, ${ }^{10}$ and there have been several published methods for the analysis of HDA in urine. ${ }^{10-15}$ Most of the published methods use acid hydrolysis with concentrated $(\geqslant 6 \mathrm{M})$ hydrochloric acid. ${ }^{12-14}$ Other studies ${ }^{11}$ have used either alkaline or acid hydrolysis, reporting slightly better recoveries for the alkaline hydrolysis. We have studied both hydrolysis techniques but have persevered with the acid hydrolysis in line with most other researchers. Use of alkaline hydrolysis gave inconsistent results and variable, sometimes high, blank values. These problems were not encountered with acid hydrolysis. The free HDA is then derivatised and analysed, usually, by gas chromatography-mass spectrometry (GCMS).

Materials and methods

SAMPLING STRATEGY

Consent for the study was obtained from the Health and Safety Executive (HSE) research ethics committee. 
Five motor vehicle repair shops that use isocyanate paints were identified by an inspector from the HSE through routine visiting and local knowledge. They consisted of two national dealerships that employ full time paint sprayers and three smaller garages (two of which had a single owner who carried out intermittent spraying, and the third, which had employees who sprayed and did other work). All followed published HSE guidance in wearing full face air fed helmets and spraying either in a ventilated booth ${ }^{16}$ or in a controlled spray space. ${ }^{17}$

It was possible to recruit both subjects (sprayers) and controls at the same place of work at three of the sites, at a fourth the unexposed person was a member of HSE staff because the sprayer worked alone. At one of the larger dealerships a group of people working just outside the spraying area were also recruited to act as bystanders. All participants were provided with an information sheet and signed a consent form after discussing the study with one of the researchers (NRW). All sprayed alone in the booth or ventilated space.

Due to the reportedly short half life (about 1.5 hours $^{13}$ ) of HDA in urine, samples were collected before, during, and after the shift to detect any short term exposure as well as an estimate of the 8 hour time weighted average exposure.

\section{PILOT STUDY}

A pilot study was undertaken in 1996 at one of the larger dealerships.

Subjects provided urine samples on the day of spraying before starting spray work, at in the middle of the shift, and at the end of the day. They recorded the amount of time spent spraying and the personal protective equipment worn. Bystanders and controls also provided three samples at the same times as the sprayers.

The samples were labelled with the person's name and either the time or the number of the sample but without the details as to whether they were sprayer, unexposed, or bystander. Samples were frozen for despatch and sent by courier to the Health and Safety Laboratory in Sheffield for analysis.

Table 1 Demography and control measures of companies involved

\begin{tabular}{ll}
\hline Company number & Demography and control measures \\
\hline 1 & $\begin{array}{l}\text { A large dealership with full time sprayers working on large vehicles in } \\
\text { a designated area with local exhaust ventilation. Sprayers wore full } \\
\text { face air fed respiratory protective equipment (RPE), disposable } \\
\text { overalls (worn with the hood down exposing the head), and latex } \\
\text { gloves. } \\
\text { This was a small garage with a single owner/sprayer carrying out } \\
\text { intermittent spraying of cars in a homemade ventilated booth. While } \\
\text { spraying he wore a full face air fed helmet with disposable overalls } \\
\text { (hood down) and no gloves. } \\
\text { A large dealership with full time sprayers carrying out car spraying in } \\
\text { a ventilated booth with full face air fed RPE, disposable overalls, and } \\
\text { latex gloves. } \\
\text { A small garage with an owner/sprayer carrying out car spraying } \\
\text { intermittently. He wore a full face air fed mask and sprayed in a } \\
\text { ventilated booth wearing disposable overalls (with the hood down) } \\
\text { and latex gloves. } \\
\text { This was a small garage with several designated sprayers who } \\
\text { sprayed cars in a ventilated booth wearing full face air fed RPE and } \\
\text { wearing disposable overalls and latex gloves. }\end{array}$ \\
&
\end{tabular}

FULL STUDY

The full study involving five companies was carried out in the same way except that because of the nature of the activities only the firm in the pilot study provided samples from bystanders. Samples were collected and despatched in a similar way, frozen and sent blind to the laboratory for analysis.

\section{ANALYTICAL PROCEDURE}

1,6-Hexanediamine (98\%), 1,7-heptanediamine (HpDA), heptafluorobutyric anhydride (HFBA), and hydrochloric acid were obtained from Aldrich. Diethyl ether and toluene (high performance liquid chromatography (HPLC) grade) were purchased from Rathburns. Sodium hydroxide solution $(10 \mathrm{M})$ and sulphuric acid were purchased from Fisher. Water was purified through a Millipore Milli-Q system. An aliquot of HpDA solution (internal standard) was added to the sample urine $(2 \mathrm{ml})$. Concentrated sulphuric acid $(200 \mu \mathrm{l})$ was then added. Samples were mixed thoroughly and then hydrolysed at $100^{\circ} \mathrm{C}$ for 90 minutes. Samples were then cooled and $2 \mathrm{ml}$ sodium hydroxide solution $(10 \mathrm{M})$ was added.

After hydrolysis, $4 \mathrm{ml}$ diethyl ether was added and the samples were extracted for 20 minutes, then centrifuged. About $3 \mathrm{ml}$ of the organic layer was transferred and evaporated to dryness under a stream of nitrogen. Samples were then resuspended in $500 \mu \mathrm{l}$ toluene and derivatised with $50 \mu \mathrm{l} \mathrm{HFBA}$ at $55^{\circ} \mathrm{C}$ for 1 hour. Samples were then cooled, evaporated to dryness, and reconstituted in $100 \mu$ toluene.

The samples were analysed by GC-MS with negative ion chemical ionisation (with methane as reagent gas). Samples ( $1 \mu \mathrm{l}$, splitless) were injected (at $350^{\circ} \mathrm{C}$ ) onto a BP-5, $25 \mathrm{~m} \times 0.32$ $\mathrm{mm}$ internal diameter fused silica capillary column ( $1 \mu \mathrm{m}$ film thickness). The oven temperature ramped from $150^{\circ} \mathrm{C}$ (initially held for 1 minute) to $280^{\circ} \mathrm{C}$ at $10^{\circ} \mathrm{C} / \mathrm{min}$ where it was held for 1.5 minutes. The interface temperature was $280^{\circ} \mathrm{C}$ and the source was held at $200^{\circ} \mathrm{C}$. With selected ion monitoring, ion $\mathrm{m} / \mathrm{z}$ 449 was monitored for HDA and m/z 462 for HpDA.

Concentrations of HDA in urine were corrected for creatinine concentration according to the method of Jaffe et al. ${ }^{18}$

\section{Results}

ANALYTICAL METHOD

The method was shown to be linear (defined as a least squares regression coefficient $>0.99$ ) over the concentration range $0-500 \mathrm{nmol} / 1$ with a detection limit of $5 \mathrm{nmol} / \mathrm{l}$. The within and between assay coefficients of variation for the method were $4 \%$ and $10 \%$ respectively $(n=10)$.

\section{PILOT STUDY}

No HDA was detected in any sample taken before the shift nor in any of the samples provided by bystanders or unexposed subjects. Low levels of HDA ( 1 and $2 \mathrm{nmol} / \mathrm{l}$ ) were detected in samples from the middle and the end of the shift respectively for two of the sprayers. 
Table 2 Urinary results and spray time details for the full study

\begin{tabular}{|c|c|c|c|c|c|c|c|}
\hline \multirow[b]{2}{*}{ Company } & \multirow[b]{2}{*}{ Worker } & \multirow[b]{2}{*}{ Sex } & \multicolumn{3}{|c|}{$\begin{array}{l}\text { HDA concentration } \\
(\mu \mathrm{mol} / \text { mol creatinine) }\end{array}$} & \multicolumn{2}{|c|}{$\begin{array}{l}\text { Spraying time }(h) \\
\text { between samples }\end{array}$} \\
\hline & & & $\begin{array}{l}\text { Sample } \\
1\end{array}$ & $\begin{array}{l}\text { Sample } \\
2\end{array}$ & $\begin{array}{l}\text { Sample } \\
3\end{array}$ & $\begin{array}{l}\text { Samples } \\
1-2\end{array}$ & $\begin{array}{l}\text { Samples } \\
2-3\end{array}$ \\
\hline \multirow[t]{10}{*}{1} & Sprayer & $M$ & 11.00 & 10.00 & 4.00 & 2.00 & 0.00 \\
\hline & Sprayer & M & ND & ND & ND & 3.00 & 2.50 \\
\hline & Sprayer & $M$ & ND & ND & ND & 3.00 & 2.50 \\
\hline & Bystander & $M$ & ND & ND & ND & NA & \\
\hline & Bystander & $M$ & ND & ND & ND & NA & \\
\hline & Bystander & $M$ & ND & 6.00 & 12.00 & NA & \\
\hline & Unexposed & $M$ & ND & ND & ND & NA & \\
\hline & Unexposed & $\mathrm{F}$ & ND & - & ND & NA & \\
\hline & Unexposed & $M$ & ND & ND & ND & NA & \\
\hline & Unexposed & $\mathrm{F}$ & ND & ND & ND & NA & \\
\hline \multirow[t]{2}{*}{2} & Sprayer & $\mathrm{M}$ & ND & ND & ND & 1.25 & 0.00 \\
\hline & Unexposed & $\mathrm{F}$ & ND & - & - & NA & \\
\hline \multirow[t]{4}{*}{3} & Sprayer & M & ND & ND & 1.00 & 0.25 & 0.10 \\
\hline & Sprayer & $M$ & ND & ND & ND & 0.30 & 0.60 \\
\hline & Sprayer & M & ND & ND & ND & 0.75 & 0.30 \\
\hline & Unexposed & $M$ & ND & ND & ND & NA & \\
\hline \multirow[t]{2}{*}{4} & Sprayer & M & ND & ND & ND & 0.75 & 0.50 \\
\hline & Unexposed & $\mathrm{F}$ & ND & ND & ND & NA & \\
\hline \multirow[t]{4}{*}{5} & Sprayer $\star$ & $M$ & ND & ND & ND & NA & \\
\hline & Sprayer & M & 1.00 & ND & ND & 3.00 & 1.00 \\
\hline & Sprayer & M & ND & 3.00 & 1.00 & 3.00 & 1.00 \\
\hline & Unexposed subject & M & ND & ND & ND & NA & \\
\hline
\end{tabular}

*No spraying undertaken on the sampling day.

- No sample provided; $\mathrm{ND}=$ none detected; $\mathrm{NA}=$ not applicable.

FULL STUDY

A total of 11 sprayers, three bystanders, and eight unexposed subjects were identified from the five participating companies. Samples were collected from all participants except for one unexposed subject who only provided two samples. The companies are described in table 1 and the urinary results are presented in table 2.

None of the unexposed subjects had detectable concentrations of HDA in any of the three samples. One bystander (company 1) had notable concentrations of HDA in samples from the middle and at the end of the shift. Four sprayers had concentrations of HDA. One in particular (company 1) had high concentrations in the samples taken before and in the middle of the shift, which fell by the end of the shift.

\section{Discussion}

ANALYTICAL METHOD

The method was shown to be linear over the concentration range studied. The coefficient of variation between assays $(10 \%)$ and detection limit $(5 \mathrm{nmol} / \mathrm{l})$ were comparable with other recently reported methods. ${ }^{12} 14$

PILOT STUDY

The pilot study showed that sprayers could receive low internal exposure to isocyanates despite wearing respiratory protective equipment and spraying in a ventilated area. It also showed that it is possible to spray isocyanates while using control measures without receiving a detectable exposure. In the pilot study none of the bystanders or unexposed subjects had any detectable concentrations of HDA.

FULL STUDY

The full study again showed that workers can absorb isocyanates during spraying operations despite wearing full face air fed masks and using ventilated spray booths or extracted work areas. Four sprayers had detectable concentrations of HDA (two had detectable concentrations in their sample before the shift) and one bystander had detectable concentrations of HDA.

Workers for small companies are not necessarily more at risk of exposure. Indeed, in this study the companies with only one sprayer (companies 2 and 4) had no detectable concentrations of HDA in urine. Also, the duration of spraying did not affect the likelihood of exposure (table 2, sprayers at company $1)$.

Biological monitoring does not determine the route of exposure-this could have been oral, dermal, or through inhalation although inhalation is the most likely route given the lack of published evidence for the absorption of isocyanates through the skin. During feedback with participants it became clear that exposure may occur when the sprayers lift their visors to inspect the quality of their work-this was reported at several garages. Field work done by the HSE has shown that isocyanate concentrations in booths and spray spaces may remain considerable $\left(>20 \mu \mathrm{g} / \mathrm{m}^{3}\right.$ (in excess of the maximum exposure limit)) for some time after spraying has stopped. Clearance times of up to 5 minutes for bespoke booths and up to 30 minutes for spray spaces have been recorded. If sprayers and other workers are not aware of the importance of clearance times they may inadvertently expose themselves sometime after spraying has finished. Similarly baking during the spray bake cycle can drive off isocyanate monomer creating considerable concentrations in the vapour within the booth or spray space during baking and for sometime after.

In the case of company 1 , the work involved spraying large lorries rather than cars and this involved some spraying above head height - an activity which may be relevant for the fit of respiratory protective equipment and subsequent detection of the metabolites in the urine of sprayers at this company.

The short initial half life of HDA means that the urine sample only represents exposure over the past $2-4$ hours. It is therefore possible that part time sprayers may have been exposed but that metabolite concentrations were too low and too quickly excreted to show that an exposure had occurred. However, it has also been reported ${ }^{14}$ that low amounts can be detected in urine 15-20 hours after an oral dose of HDA. There is therefore the possibility of accumulation of HDA in the body during the working week.

Recent work on other isocyanates ${ }^{3}$ has also shown that other adducts of isocyanate in plasma may break down over time causing excretion of the diamine metabolites for an extended period. Concentrations of toluene diamine (up to $5 \mu \mathrm{mol} / \mathrm{mol}$ creatinine) could be detected several days, even weeks, after exposure had ended. It is possible that this may also be true for HDA.

However, the concentration found in the samples reported here is higher than previously reported for adduct breakdown, and the wash out found would be more consistent with the 
initial half life (1.5-2 hours) than adduct breakdown. It would therefore seem that the most likely explanation of the positive samples before the shift would be an inadvertent short term high exposure before the sample was provided. The sprayer at company 1 with positive concentrations of HDA had a possible exposure before the sample taken before the shift. Urinary concentrations of HDA were maintained while spraying for 3 hours before the sample taken in the middle of the shift. Between providing that sample and the one taken after the shift no spraying was undertaken; this is reflected in the drop in the urinary HDA concentration (suggesting a half life consistent with that reported of about 2 hours).

In the case of the bystander at company 1 discussion with the person showed that while not spraying himself he did think that he may have gone to speak to a sprayer at work.

The concentrations of HDA detected in this study are similar to those found in other studies. ${ }^{13}{ }^{14}$ Brorson et $a l^{13}$ reported a mean value of HDA after the shift of $20 \mu \mathrm{mol} / \mathrm{mol}$ creatinine after 7.5 hours exposure to $25 \mu \mathrm{g} / \mathrm{m}^{3}$ HDI whereas Maitre et $a l^{14}$ measured a value of $12 \mu \mathrm{mol} / \mathrm{mol}$ creatinine for HDI exposure at the same concentration from a survey of workers.

The study has shown that it is possible to spray isocyanates without exposure to them if respiratory protective equipment and suitable extraction is provided but the results also suggest that exposure can occur despite the use of such precautions. Much effort has rightly gone into publicising the importance of the selection, fit, and maintenance of respiratory protective equipment; such effort will be wasted if consideration is not also given to the behaviour which workers adopt to do their job-that is, a human factors approach to prevention of ill health due to isocyanates is needed.

\section{Conclusion}

This study has shown that exposure to isocyanates can occur despite the use of full respiratory protective equipment and ventilated booths. It has also shown that urinary metabolites (HDA) can be used to identify these exposures and to assess the adequacy of controls. The evidence of exposure despite precautions highlights the continued need to improve control procedures, to provide health surveillance to check the efficacy of controls, and to provide information and instruction and training for workers in motor vehicle repair shops.
Further work is recommended to conduct a cross sectional industrial survey and the possible establishment of a biological monitoring benchmark value to assess control of exposure.

This study was supported by the Health and Safety Executive. We acknowledge the assistance of Mr Jon Harper, HM Inspector of Health and Safety, in the identification and recruitment of companies for the study.

1 Meredith SK, McDonald JC. Work related respiratory disease in the united Kingdom 1989-92: report on the SWORD project. Occup Med 1994;44:183-9.

2 Siriruttanapruk S, Burge PS. Annual report of SHIELD in 1996 on behalf of the Midlands Thoracic Society Research Group. Circulated to participating physicians. Birmingham: MTSRG, 1996.

3 Lind P, Dalene M, Skarping G, et al. Toxicokinetics of 2,4and 2,6-toluenediamine in hydrolysed urine and plasma after occupational exposure to 2,4- and 2,6-toluene diisocyanate. Occup Environ Med 1996;53:94-9.

4 The Stationery Office. Control of substances hazardous to health regulations 1994: approved codes of practice. London: SO, 1994.

5 Karol MH, Hauth BA, Riley EJ, et al. Dermal contact with toluene diisocyanate produces respiratory tract hypersensitivity in guinea pigs. Toxicol Appl Pharmacol 1981;58:22130.

6 Rattray NJ, Botham PM, Hext PM, et al. Induction of respiratory hypersensitivity to MDI in guinea pigs. Influence of route of exposure. Toxicology 1994;88:15-30.

7 Maitre A, Berode M, Stoklov M, et al. Human skin penetration study of hexamethylene diisocyanate (HDI) by using biological monitoring to hexamethylene diamine (HDA). International Symposium on Biological Monitoring in Occupational and Environmental Health. 1996. ISBN 951-802tional 8 .

8 Redlich CA, Karol MH, Graham C, et al. Airway isocyanate-adducts in asthma induced by exposure to 1,6hexamethylenediisocyanate. Scand $\mathcal{f}$ Work Environ Health 1997;23:227-31

9 Hazardous substances databank. Computerised database service. Washington, DC: HSDB, 1993.

10 Rosenberg C, Savolainen H. Determination in urine of diisocyanate-derived amines from occupational exposure by gas chromatography-mass fragmentography. Analyst by gas chromatograp

11 Dalene M, Skarping G, Tinnerberg H. Biological monitoring of hexamethylene diisocyanate by determination of 1,6-hexamethylene diamine as the trifluoroethyl chloroformate derivative using capillary gas chromatography with thermionic and selective ion monitoring. $\mathcal{f}$ Chromatogr $B$ Biomed Appl 1994;656:319-28.

12 Dalene M, Skarping G, Brorson T. Chromatographic determination of amines in biological fluids with special mination of amines in biological fluids with special amines. IV. Determination of 1,6-hexamethylenediamine in human urine using capillary gas chromatography and human urine using capillary gas chromatography and

13 Brorson T, Skarping G, Nielsen J. Biological monitoring of isocyanates and related amines. II Test chamber exposure of humans exposed to 1,6-hexamethylene diisocyanate (HDI). Int Arch Occup Environ Health 1990;62:385-9.

14 Maitre A, Berode M, Perdix A, et al. Urinary hexane diamine as an indicator of occupational exposure to diamine as an indicator of occupational exposure to 1996;69:65-8.

15 Skarping G, Dalene M, Tinnerberg H. Biological monitoring of hexamethylene and isophorone isocyanate by the determination of hexamethylene and isophorone diamine in hydrolysed urine using liquid chromatography and mass spectrometry. Analyst 1994;119:2051-5.

16 Health and Safety in Engineering Workshops (HS(G)129). London: Health and Safety Executive, 1997.

17 Health and Safety in Motor Vehicle Repair (HS(G)67). London: Health and Safety Executive, 1991.

18 Jaffe $M$. Measurement of creatinine using picric acid. $Z$ Physiol Chem 1886;10:391-400. 